\title{
PENGARUH INTEGRASI TERNAK KAMBING DAN TANAMAN KOPI TERHADAP PENDAPATAN KELOMPOK TANI TERNAK SATWA AMERTA, DI DESA MUNDEH, KECAMATAN SELEMADEG BARAT, KABUPATEN TABANAN
}

\author{
I Gusti Agung Nyoman Dananjaya, S.P.,M.Agb. \\ Program Studi Agribisnis, Fakultas Pertanian, Universitas Dwijendra, \\ Email: guz.d4nan@gmail.com
}

\begin{abstract}
Abstrak
Pembangunan sektor pertanian yang termasuk didalamnya sektor perkebunan dan peternakan merupakan salah satu upaya meningkatkan pendapatan petani, maka seluruh sektor ini harus dilaksanakan secara terintegrasi. Penelitian ini bertujuan untuk menganalisis pengaruh integrasi ternak kambing dan tanaman kopi terhadap pendapatan Kelompok Tani Ternak Satwa Amerta, di Desa Mundeh, Kecamatan Selemadeg Barat, Kabupaten Tabanan. Penentuan lokasi penelitian ini menggunakan metode purposive sampling yaitu penentuan lokasi penelitian dengan cara sengaja dengan pertimbangan bahwa Kelompok Tani Ternak Satwa Amerta melaksanakan program integrasi antara ternak dan tanaman. Popoulasi dalam penelitian ini adalah Kelompok Tani Ternak Satwa Amerta yang berjumlah 21 orang. Teknik pengambilan sampel dalam penelitian ini menggunakan metode sensus sehingga seluruh populasi dijadikan sebagai responden. Tekni Analisis data menggunakan analisis SEM dengan alat ansalisis PLS (Partial Least Square).

Hasil penelitian menunjukkan bahwa ternak kambing berpengaruh positif dan signifikan terhadap pendapatan, demikian juga terhadap tanaman kopi. Tanaman kopi ternyata berpengaruh positif dan sangat signifikan terhadap pendapatan. Hal ini menunjukkan bahwa integrasi ternak kambing besar pengaruhnya dalam menyuburkan tanaman kopi sehingga dapat mampu meningkatkan pendapatan pada Kelompok Tani Ternak Satwa Amerta di Desa Mundeh, Kecamatan Selemadeg Barat, Kabupaten Tabanan. Saran bagi kelompok tani ternak yaitu untuk terus melakukan pemupukan dari hasil kotoran ternak kambing dalam jumlah dan waktu yang tepat pada tanaman kopi dan peningkatan pelatihan di kelompok tani ternak sebagai media pembelajaran terhadap kemajuan teknologi-teknologi terbaru.
\end{abstract}

Kata Kunci : Integrasi, Tanaman Kopi, Ternak Kambing, Pendapatan

\begin{abstract}
Abtract
The development of the agricultural sector, which includes the plantation and livestock sector, is an effort to increase farmer' income, so all these sectors must be implemented in an integrated mannner. This study aims to analyze the effect of the integration of goats and coffee plants on the income of the Amerta Animal Farmers Group in Mundeh Village, West Selemadeg District, Tabanan Regency. Determination of the location of this study deliberately with the consideration that the Amerta Farmer Group implements an integration program between livestock and plants. The population in this study is the Amerta Animal Farmer Group, Amounting to 21 people. The sampling technique in this study used a census method so that the entire population was used as respondents. Data analysis techniques used SEM analysis with PLS (Partial Least Square) analysis tools.

The result showed that goat livestock had a positivie and significant effet on income, as well as on the coffee plant. Coffee plants have a positive and very significant effect on income. This shows that the integration of large goat livestock has an effect on fertilizing coffee plants so that it can increase income in the Amerta Animal Farmer groups are to continue to carry out fertilization from the result of goat manure in the right amount and time on coffee plants and increase training in livestock farmer groups as a learning medium for the latest technological advances.
\end{abstract}

Keywords : Integration, Coffee Plants, Goats, Income

\section{PENDAHULUAN}

Pembangunan pertanian di Indonesia merupakan sektor paling terpenting dari keseluruhan pembangunan ekonomi untuk meningkatkan kesejahteraan petani. Dalam pembangunan sektor pertanian harus dilaksanakan secara berkelanjutan melalui pengembangan kemampuan petani dalam mengelola usahataninya, agar selalu memiliki produktivitas yang sangat tinggi dan mampu meningkatkan pendapatan petani. Pembangunan sektor pertanian yang termasuk didalamnya sektor perkebunan dan 
peternakan merupakan salah satu upaya meningkatkan pendapatan petani, maka seluruh sektor ini harus dilaksanakan secara terintegrasi.

Pembangunan pertanian memiliki peran yang strategis dalam perekonomian nasional. Peran strategis pertanian tersebut digambarkan melalui kontribusi yang nyata melalui pembentukan capital, penyediaan bahan pangan, bahan baku industri, pakan dan bioenergi, penyerap tenaga kerja, sumber devisa Negara, sumber pendapatan, serta pelestarian lingkungan melalui praktek usahatani yang ramah lingkungan. Para pakar ekonomi menyadari bahwa pembangunan pertanian bersama-sama pembangunan perdesaan, dianggap sebagai syarat mutlak bagi pelaksanaan dan keberhasilan pembangunan nasional suatu negara di Dunia Ketiga. Tanpa adanya pembangunan pertanian dan perdesaan yang benar-benar serius, maka pembangunan sektor industri gagal. Seandainya berhasil, akan menciptakan ketergantungan ekonomi dan berbagai bentuk ketimpangan sosial ekonomi (Prayitno dan Santosa, 1996).

Berbagai inovasi teknologi pertanian telah berhasil dilahirkan dan dikembangkan oleh Badan Penelitian dan Pengembangan (Litbang) Pertanian. Teknologi-teknologi tersebut telah memberikan andil yang cukup besar terhadap pembangunan pertanian. Namun demikian, evaluasi eksternal dan internal menunjukkan bahwa kecepatan dan tingkat pemanfaatan inovasi yang dihasilkan Badan Litbang Pertanian cenderung melambat, bahkan menurun. Hal ini mengindikasikan bahwa segmen rantai pasok inovasi pada subsistem penyampaian (delivery subsystem) dan subsistem penerima (receiving subsystem) merupakan bottleneck yang menyebabkan kelambanan penyampaian informasi dan rendahnya tingkat adopsi inovasi yang dihasilkan Badan Litbang Pertanian (Simatupang, 2004).

Salah satu sistem usahatani yang dapat mendukung pembangunan pertanian di wilayah perdesaan adalah sistem integrasi tanaman-ternak. Ciri utama dari pengintegrasian tanaman dengan ternak adalah adanya keterkaitan yang saling menguntungkan antara tanaman dan ternak. Keterkaitan tersebut terlihat dari pembagian lahan yang saling terpadu dan pemanfaatan limbah dari masing masing komponen.

Saling keterkaitan berbagai komponen sistem integrasi merupakan faktor pemicu dalam mendorong pertumbuhan pendapatan masyarakat tani dan pertumbuhan ekonomi wilayah yang berkelanjutan (Pasandaran, $d k k$., 2005). Diungkapkan bahwa, sistem integrasi tanaman ternak mengemban tiga fungsi pokok yaitu memperbaiki kesejahteraan dan mendorong pertumbuhan ekonomi, memperkuat ketahanan pangan dan memelihara keberlanjutan lingkungan.

Sistem integrasi tanaman-ternak merupakan usaha pertanian terpadu yang sangat efisien dan telah menjadi bagian dari budaya bertani masyarakat petani di Indonesia. Kearifan lokal ini perlu terus dikembangkan dan dibina dengan baik sehingga mampu meningkatkan pendatan petani. Sistem usahatani ini dapat dikembangkan berdasarkan konsep Low External Input Sustainable Agriculture (LEISA), dengan cara: (1) pemanfaatan limbah tanaman sebagai pakan ternak, (2) pemanfaatan kotoran ternak dan limbah tanaman non pakan menjadi kompos untuk memperbaiki sifat fisik, kimia, dan biologi tanah, dan (3) penggembalaan ternak diarahkan untuk memakan tanaman liar/gulma (Diwyanto, $d k k$., 2004).

Di Provinsi Bali salah satu desa di Kabupaten Tabanan yang memiliki perkebunan kopi yaitu Desa Mundeh. Sektor pertanian adalah sektor andalan pendapatan masyarakat di Desa Mundeh, lebih dari $80 \%$ masyarakatnya bergelut di sektor pertanian dan sejak beberapa tahun terakhir ini banyak permasalahan yang dihadapi dalam sektor pertanian. Berbagai kebutuhan sarana produksi pertanian harganya terus 
meningkat, di sisi lain produksi pertanian selalu mengalami penurunan harga jual terutama pada saat panen raya tiba. Disamping itu juga kepemilikan lahan petani dengan terdesaknya oleh berbagai kepentingan setiap tahunnya terus mengalami alih fungsi lahan menjadi pemukiman sehingga berdampak pada meningkatnya jumlah kemiskinan.

Sistem integrasi tanaman-ternak mengandung arti bahwa kedua usaha diharapkan berlangsung dalam satu sistem usaha agribisnis Crop-Livestock Systems (CLS) yang saling mengisi, yaitu dari tanaman tersedia input berupa pakan dan dari ternak termanfaatkan kotoran ternak menjadi pupuk organik (Djayanegara dan Ismail, 2004). Salah satu kelompok tani yang menjalakan program terintegrasi adalah Kelompok Tani Ternak Satwa Amerta. Kelompok tani tersebut sudah menjalakan usahatani terintegrasinya sudah dari dulu, tetapi dalam pelaksanaan program tersebut belum maksimal. Masih ada beberapa limbah ternak kambing yang belum difermentasi. Sehingga hasil integrasi ternak dan tanaman tersebut belum optimal. Terkait permasalahan tersebut tujuan penelitian ini adalah untuk menganalisis pengaruh integrasi ternak kambing dan tanaman kopi terhadap pendapatan di Kelompok Tani Ternak Satwa Amerta

\section{METODE}

Penelitian ini dilakukan pada Kelompok Tani Ternak Satwa Amerta, Desa Mundeh, Kecamatan Selemadeg Barat, Kabupaten Tabanan. Pemilihan lokasi ini ditentukan secara purposive sampling yaitu teknik penentuan sampel lokasi secara sengaja atau dengan pertimbangan tertentu. Adapun pertimbangannya adalah pada Kelompok Tani Satwa Amerta memiliki ternak kambing dan mengusahatanikan tanaman kopi serta melaksanakan program integrasi antara ternak dan tanaman. Populasi pada penelitian ini adalah seluruh anggota Kelompok Tani Satwa Amerta yang berjumlah 21 orang. Teknik engambilan sampel pada penelitian ini menggunakan metode sensus sehingga seluruh populasi dijadikan responden.

Data yang digunakan dalam penelitian ini meliputi data primer dan data sekunder baik yang bersifat kualitatif maupun kuantitatif yang berkenaan dengan integrasi ternak kambing, tanaman kopi dan pendapatan Kelompok Tani Ternak Satwa Amerta. Sedangkan teknik pengumpulan data dilakukan dengan menggunakan kuesioner, wawancara, observasi dan dokumentasi.

Metode analisis data yang digunakan dalam penelitian ini adalah analisis SEM dengan alat ansalisis PLS (Partial Least Square). Dalam penelitian ini terdapat dua variabel eksogen yaitu Usaha Ternak Kambing $\mathrm{X}_{1}$, Usahatani Tanaman Kopi $\mathrm{X}_{2}$, sedangkan variabel endogennya adalah Pendapatan ( $\mathrm{Y}$ ). Variabel-variabel tersebut merupakan variabel laten yang diukur dari beberapa indikator. Tiap-tiap indikator terdiri atas beberapa item yang dijabarkan dalam instrumen penelitian sebagai variabel terobservasi.

Usaha Ternak Kambing $\left(\mathrm{X}_{1}\right)$ yang terdiri dari populasi ternak kambing $\left(\mathrm{X}_{1.1}\right)$, produksi kotoran kambing $\left(\mathrm{X}_{1.2}\right)$, jumlah pakan $\left(\mathrm{X}_{1.3}\right)$, harga kambing per ekor $\left(\mathrm{X}_{1.4}\right)$, biaya tenaga kerja $\left(\mathrm{X}_{1.5}\right)$. Usahatani Kopi $\left(\mathrm{X}_{2}\right)$ yang terdiri dari luas lahan tanaman kopi $\left(\mathrm{X}_{2.1}\right)$, jumlah produksi $\left(\mathrm{X}_{2.2}\right)$, jumlah pupuk $\left(\mathrm{X}_{2.3}\right)$, harga kopi $\left(\mathrm{X}_{2.4}\right)$, biaya tenaga kerja $\left(\mathrm{X}_{2.5}\right)$. Pendapatan $(\mathrm{Y})$ yang terdiri dari 2 indikator yaitu pendapatan usaha ternak kambing $\left(\mathrm{Y}_{1}\right)$, dan pendapatan usahatani kopi $\left(\mathrm{Y}_{2}\right)$. 
Data yang diperoleh dari hasil distribusi kuesioner, selanjutnya dianalisis menggunakan Partial Least Square (PLS) yang diaplikasikan dalam software Smart-PLS. Alasan digunakan metode analisis PLS ini, karena tidak mengasumsikan data harus menggunakan pengukuran skala tertentu, digunakan pada jumlah sampel kecil (20- 50 unit atau < 100 unit), dan juga dapat digunakan untuk konfirmasi teori (Ghozali,2008).

\section{HASIL DAN PEMBAHASAN}

\section{Gambaran umum Desa Mundeh}

Desa Mundeh berada dalam lingkup Kecamatan Selemadeg Barat, Kabupaten Tabanan dengan jarak tempuh 18 km dari kota Kecamatan dan 40 KM dari Kota Kabupaten dengan jarak tempuh kurang lebih 1 jam, memiliki luas wilayah sekitar 1.414,659 Ha. Pemerintahan Desa Mundeh terbagi atas 8 Banjar Dinas yaitu : Banjar Dinas Yeh Kayu, Banjar Dinas Pancoran Kelod, Banjar Dinas Pancoran, Banjar Dinas Nyuhgading, Banjar Dinas Pengedan, Banjar Dinas Bangal, Banjar Dinas Auman Delod Sema, Banjar Dinas Auman Dajan Sema, saat ini berdasarkan sensus tahun 2010 penduduk Desa Mundeh berjumlah : 2665 orang, laki - laki :1.335 jiwa, Perempuan : 1.329 Jiwa terdiri dari 829 KK yang didalamnya terdapat 59 KK miskin (211 jiwa). Saat ini fasilitas yang ada di Desa Mundeh antara lain : 2 Sekolah Dasar dengan 201 anak didik yang sampai saat ini masih kekurangan tenaga pengajar (guru), 1 TK, 2 Kelompok Bermain (PAUD), 1 Puskesmas Pembantu.

Dari segi kependudukan jenis pekerjaan masyarakat masih didominasi sebagai petani perkebunan ( $80 \%$ ), sedangkan sektor yang menonjol dalam penyerapan tenaga kerja, perdangan $1 \%$, sektor jasa angkutan $1 \%$, dan sektor lain seperti pegawai negeri,karyawan swasta dari berbagai sektor $18 \%$,. Desa Mundeh memiliki jalan sepanjang 28,800 Km dengan rincian : Jalan Nasional 0 Km,jalan Propinsi 6 Km, Jalan Kabupaten 12,5 Km,Jalan Desa 4,7 Km,Jalan Dusun 5,6 Km dengan kondisi beraspal 7,5 Km , Beton sepanjang 9,5, Jalan geladag 1,5 Km,jalan Tanah sepanjang 5,3Km. Struktur penduduk menurut pendidikan menunjukkan kwalitas sumber daya manusia yang dipunyai Desa Mundeh Yaitu yang berusia pada usia pendidikan dasar 7 tahun s/d 16 tahun (pendidikan sekolah dasar dan menengah) yang belum pernah sekolah $1,75 \%$, sedang mengikuti pendidikan $90 \%$ dan sisanya 8,25\% tidak bersekolah lagi. Sedangkan yang berusia diatas 16 tahun (diatas usia pendidikan dasar) yang belum pernah sekolah $0 \%$, sedang mengikuti pendidikan $90 \%$ dan sisanya $10 \%$ tidak bersekolah lagi.

\section{Profil Kelompok Tani Ternak Satwa Amerta}

Poktan ini bernama Kelompok Tani Ternak Satwa Amerta yang memiliki arti kurang lebih adalah memanfaatkan isi alam untuk meraih hasil yang optimal, yang selalu tertumpu pada pemeliharaan ternak, dari ternak itu mendapatkan hasil mengganda yakni: Hasil pemeliharaannya ( Ternak ) dan kotoran yang dihasilkan oleh ternak itu sendiri. Berkat itulah masyarakat memelihara ternak dengan tujuan hidup akan lebih mudah tercapai yaitu kesejahteraan lahir dan batin. Pada Saat dikukuhkan anggota Kelompok Tani Ternak Satwa Amerta ini beranggotakan 21 orang. Poktan ini berdiri pada tanggal 19 Agustus 2014. Alamat Kelompok Tani Ternak Satwa Amerta berada di Banjar Pancoran, Desa Mundeh, Kecamatan Selemadeg Barat, Kabupaten Tabanan. Kelompok Tani Ternak Satwa Amerta ini di dirikan pada tahun 
2014 dan di kukuhkan oleh Perbekel Desa Mundeh Bapak I Nyoman Sunarsa pada tanggal 19 Agustus 2014 ber nomor 124/MND/VIII/2014.

Luas wilayah Subak Dayang Pancoran di Br Pancoran, Desa Mundeh Kecamatan Selemadeg Barat, Kabupaten Tabanan 115 Ha dengan pengembangan tanaman pangan seperti Kopi, Kakao, Pisang, Kelapa dan komoditas lain seperti cengkeh dan durian, yang ada ditegalan seperti manggis. Pada sektor peternakan pengembangan kambing PE betina sebanyak 40 ekor untuk mendukung peningkatan produksi pupuk dan meningkatkan populasi ternak kambing di wilayah Desa Mundeh

Anggota Poktan yang semuanya adalah petani mempunyai usaha Pokok Ternak disamping usahausaha lainnya di bidang pertanian dalam arti luas yaitu Berternak Babi, , Petani dan lainnya disamping anggota bekerja sambilan sebagai buruh bangunan memberikan tambahan penghasilan bagi mereka dan keluarganya. Untuk mengembangkan tanaman organik di Desa Mundeh perlu peran serta dari semua pihak, baik petani, Pemerintah, Pengusaha dan Perguruan Tinggi sehingga Bali menjadi Pulau Organik lebih cepat tercapai.

\section{Hasil Analisis Pengaruh Integrasi Ternak Kambing dan Tanaman Kopi terhadap Pendapatan Kelompok Tani Ternak Satwa Amerta}

Berdasarkan hasil penelitian Pengujian terhadap model struktural dilakukan dengan melihat nilai $R$ Squares untuk setiap variabel sebagai kekuatan prediksi dari model struktural. Selain melihat besarnya nilai $R$-Squares, evaluasi model struktural PLS dapat juga dilakukan dengan $\mathrm{Q}^{2}$ predictive relevance atau sering disebut predictive sample reuse. Besaran $\mathrm{Q}^{2}$ memiliki nilai rentang $0<\mathrm{Q}^{2}<1$, semakin mendekati 1 berarti model struktural dari suatu penelitian semakin baik. Hasil pengujian model dapat dilihat pada Tabel 1.

Tabel 1

Hasil Evaluasi Goodness of Fit

\begin{tabular}{|l|c|}
\hline \multicolumn{1}{|c|}{ Variabel } & R square \\
\hline Usahatani Kopi $\left(\mathrm{X}_{1}\right)$ & 0.656 \\
Pendapatan $(\mathrm{Y})$ & 0.726 \\
\hline Kalkulasi : & \\
$\mathrm{Q}^{2}=1-\left(1-\mathrm{R}_{1}{ }^{2}\right)\left(1-\mathrm{R}_{2}{ }^{2}\right)\left(1-\mathrm{R}^{2}\right)$ & \\
$\mathrm{Q}^{2}=1-(1-0.656)(1-0.726)=\mathbf{0 . 9 0 5}$ & \\
\hline
\end{tabular}

Sumber : Hasil Analisis Data Responden

Hasil evaluasi Tabel 1 menunjukkan bahwa model struktural terbukti nilai $Q^{2}(0.905)$ mendekati angka 1. Dengan demikian hasil evaluasi ini memberi bukti bahwa model struktural memiliki kesesuaian (goodness of fit model) yang baik. Hal ini berarti bahwa informasi yang terkandung dalam data 90,5\% dapat dijelaskan oleh model sedangkan sisanya 9,5\% dijelaskan variabel lain yang belum terdapat dalam model.

Pengujian koefisien jalur struktural dilakukan untuk menjawab hipotesis penelitian dan juga untuk mengetahui besarnya pengaruh masing-masing variabel. Hasil pengujian model dan hipotesis dapat dilihat pada Tabel 2. 
Tabel 2

Koefisien Jalur Struktural

\begin{tabular}{|l|c|c|c|}
\hline \multicolumn{1}{|c|}{ Hubungan Antar Variabel } & $\begin{array}{c}\text { Koefisien } \\
\text { Jalur }\end{array}$ & T-Statistic & Keterangan \\
\hline Usaha Ternak Kambing $\left(\mathrm{X}_{1}\right)$-> Pendapatan $(\mathrm{Y})$ & 0.646 & 8.514 & $\begin{array}{c}\text { Positif dan Sangat } \\
\text { Signifikan }\end{array}$ \\
\hline $\begin{array}{l}\text { Usahatani Ternak Kambing }\left(\mathrm{X}_{1}\right) \text {-> Usahatani } \\
\text { Kopi }\left(\mathrm{X}_{2}\right)\end{array}$ & 0.852 & 14.332 & $\begin{array}{c}\text { Positif dan Sangat } \\
\text { Signifikan }\end{array}$ \\
\hline Usahatani Kopi $\left(\mathrm{X}_{2}\right)$-> Pendapatan $(\mathrm{Y})$ & 0.726 & 12.980 & $\begin{array}{c}\text { Positif dan Sangat } \\
\text { Signifikan }\end{array}$ \\
\hline
\end{tabular}

Sumber : Hasil Analisis Data Responden

Berdasarkan informasi dari Tabel 2 di atas, maka hasil pengujian hipotesis yang diajukan dalam penelitian ini dapat dijelaskan sebagai berikut:

\section{Pengaruh usaha ternak kambing terhadap pendapatan Kelompok Tani Ternak Satwa Amerta}

Berdasarkan hasil analisis Smart PLS dapat diketahui bahwa usaha ternak kambing berpengaruh positif dan sangat signifikan terhadap pendapatan. Pengaruh usaha ternak kambing terhadap pendapatan dapat diibuktikan dengan nilai $t_{\text {hitung }}>\mathrm{t}_{\text {tabel }}(8.514>2.83)$. Hal ini menunjukkan bahwa usaha ternak kambing menjadi dasar usaha ternak untuk dapat meningkatkan kesejahteraan dan pendapatan kelompok Tani Ternak Satwa Amerta. Hal ini dapat dilihat dari kemampuan kelompok dalam beternak kambing. Dilihat dari pengaruh tidak langsung, usaha ternak kambing melalui usahatani kopi berpengaruh terhadap pendapatan kelompok tani ternak. Ini menunjukan bahwa dengan usaha ternak kambing dan usahatani kopi dapat meningkatkan pendapatan kelompok tani ternak. Dengan memiliki usaha ternak kambing maka akan dapat mengintegrasikan dengan tanaman kopi. Sehingga hasil dari integrasi tersebut akan meningkatkan pendapatan petani. Hasil dari berternak kambing selain dari mendapatkan anaknya, peternak juga bisa mendapatkan kototan kambing yang berupa padat dan cair. Kotoran tersebut difermentasi dan hasilnya di terapkan pada tanaman kopi. Indikator usaha ternak kambing yang paling dominan dalam mencapai peningkatan pendapatan adalah jumlah produksi kotoran ternak kambing. Hal ini dilihat dari terus meningkatnya kelahiran ternak di Kelompok Tani Ternak Satwa Amerta sehingga penjualan kambing terus meningkat dan jumlah kotoran yang semakin meningkat untuk diolah menjadi pupuk organik

\section{Pengaruh usaha ternak kambing terhadap usahatani kopi}

Berdasarkan hasil analisis Smart PLS dapat diketahui bahwa usaha ternak kambing berpengaruh positif dan sangat signifikan terhadap usahatani kopi pada Kelompok Tani Terna Satwa Amerta. Pengaruh usaha ternak kambing terhadap usahatani kopi dapat dibuktikan dengan nilai $\mathrm{t}_{\text {hitung }}>\mathrm{t}_{\text {tabel }}$ (14.332 > 2.83). Hal ini menunjukkan bahwa hasil usaha ternak kambing dapat membantu usahatani kopi. Hal ini dilihat dari limbah kotoran kambing yang dapat diolah menjadi pupuk organik. Limbah kotoran tersebut digunakan untuk memupuk tanaman kopi sehingga hasil panen dan jumlah produksi buah kopi yang semakin meningkat dan berkualitas. Indikator usahatani kopi yang paling dominan adalah jumlah produksi. Jumlah produksi kopi yang semakin meningkat dapat meningkatkan hasil penjualan dari petani kopi. 


\section{Pengaruh usatani kopi terhadap pendapatan Kelompok Tani Ternak Satwa Amerta}

Berdasarkan hasil analisis Smart PLS dapat diketahui usahatani kopi berpengaruh positif dan sangat signifikan terhadap pendapatan Kelompok Tani Ternak Satwa Amerta. Pengaruh usahatani kopi dapat dibuktikan dengan nilai $t_{\text {hitung }}>t_{\text {tabel }}(12.980>2.83)$. Hal ini menunjukkan bahwa pendapatan kelompok tani ternak telah mengusahatanikan tanamam kopi sehingga pendapatan semakin meningkat disamping dari beternak kambing. Indikator pendapatan yang paling dominan adalah pendapatan ternak kambing. Ini menunjukkan pendapatan ternak kambing yang lebih besar. Maka dari itu untuk meningkatkan pendapatan petani tidak bisa dari sektor pertanian saja, tetap harus dibarengi juga oleh sektor peternakan. Dari hasil integrasi ternak kambing dan tanaman kopi ini diharapkan mampu meningkatkan lebih tinggi lagi dari sebelumnya, sehingga dapat meningkatkan kesejahteraan petani pada Kelompok Tani Ternak Satwa Amerta.

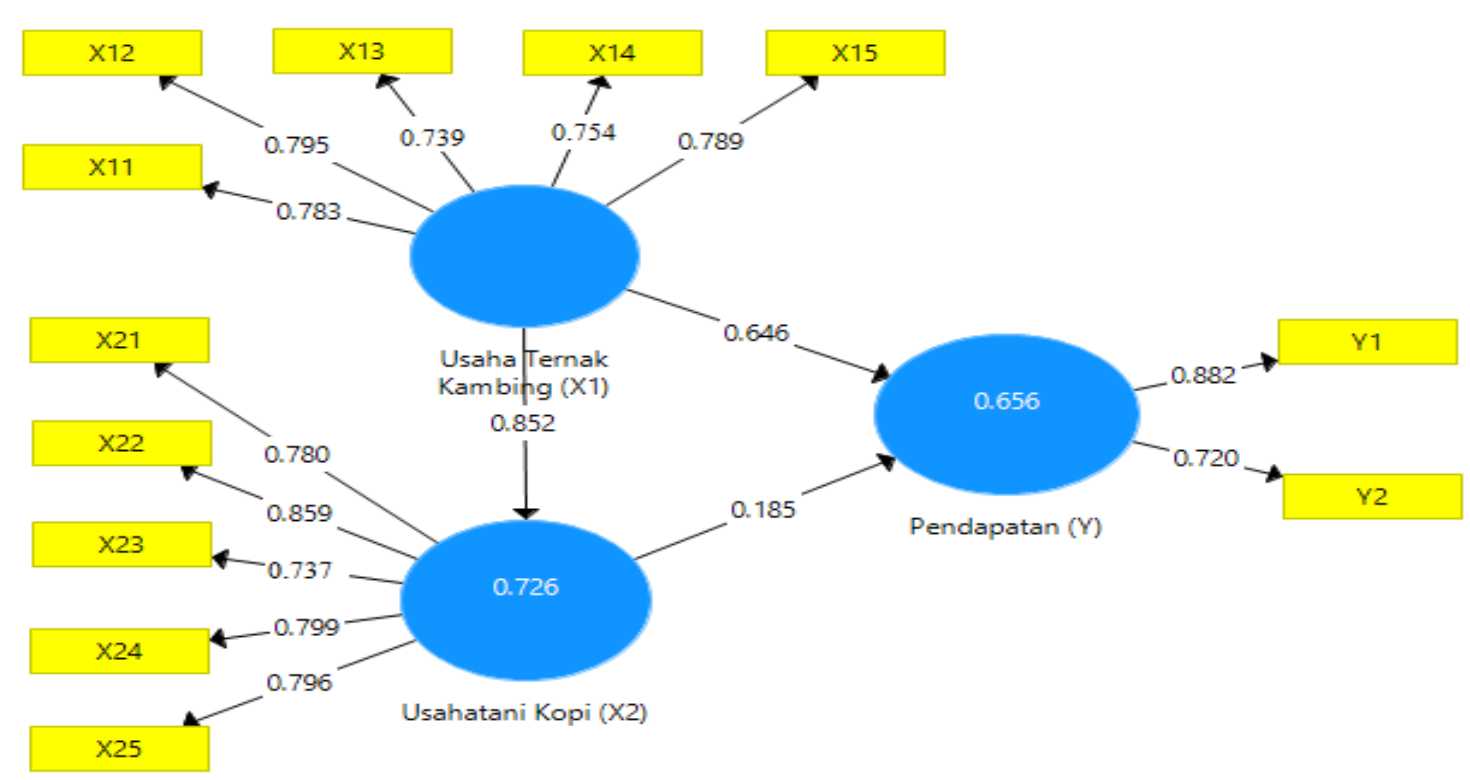

Gambar 1

Model Struktural

\section{PENUTUP}

\section{Simpulan}

Berdasarkan hasil dan pembahasan di atas dapat disimpulkan bahwa (1) usaha ternak kambing berpengaruh positif dan sangat signifikan terhadap pendapatan Kelompok Tani Ternak Satwa Amerta. Indikator usaha ternak kambing yang paling dominan adalah jumlah produksi kotoran ternak kambing. (2) usaha ternak kambing berpengaruh positif dan sangat signifikan terhadap usahatani kopi pada Kelompok Tani Ternak Satwa Amerta. Indikator usahatani kopi yang paling dominan adalah jumlah produksi kopi. 
(3) usahatani kopi berpengaruh positif dan sangat signifikan terhadap pendapatan Kelompok Tani Ternak Satwa Amerta. Indikator pendapatan yang paling dominan adalah pendapatan ternak kambing.

Saran

Berdasarkan hasil analisis dan pembahasan yang telah dilakukan dalam penelitian ini, maka dapat diberikan beberapa saran sebagai yaitu (1) bagi kelompok tani ternak yaitu untuk terus melakukan pemupukan dari hasil kotoran ternak kambing dalam jumlah dan waktu yang tepat pada tanaman kopi dan (2) peningkatan pelatihan di kelompok tani ternak sebagai media pembelajaran terhadap kemajuan teknologi-teknologi terbaru.

\section{DAFTAR PUSTAKA}

Arya, NN., K.B. Susrusa dan M.N. Tenaya. 2014. Pengaruh primatani terhadap peningkatan pendapatan petani perkebunan di Kecamatan Busungbiru. J. Manajemen Agribisnis. 2 (1):22-35.

Diwyanto, K., D. Sitompul, I. Manti, I-W Mathius dan Soentoro. 2004. Pengkajian Pengembangan Usaha Sistem Integrasi Kelapa Sawit-Sapi. Prosiding Lokakarya Nasional Sistem Integrasi Kelapa Sawit-Sapi. Departemen Pertanian bekerjasama dengan PemProp. Bengkulu dan PT. Agricinal.

Djayanegara, A. dan I. G. Ismail. 2004. Manajemen Sarana Usaha Tani Dan Pakan Dalam Sistem Integrasi Tanaman Ternak. Workshop Kelembagaan Usaha Tanaman-Ternak Terpadu Dalam Sistem dan Usaha Agribisnis, Denpasar tanggal 30 November-2 Desember 2004.

Ghozali, I. 2008. Structural Equation Modeling Metode Alternatif dengan Partial Least Square. Edisi 2. Semarang : Universitas Diponegoro.

Pasandaran, E., A. Djayanegara, K. Kariyasa, dan F. Kasryno. 2005. Integrasi Tanaman Ternak di Indonesia. Badan penelitian dan Pengembangan Pertanian. Jakarta.

Prayitno, H. dan Budi Santosa. 1996. Ekonomi Pembangunan. Cetakan Pertama. Jakarta:Ghalia Indonesia.

Simatupang, P. 2004. Primatani Sebagai Langkah Awal Pengembangan Sistem dan Usaha Agribisnis Industrial. Analisis Kebijakan Pertanian, 2 (3): 209-225.

Soekartawi. 1995. Pembangunan Pertanian. Jakarta: PT Raja Grafindo Persada.

Sugiyono, 2006. Metode Penelitian Bisnis. Bandung: CV. Alfabeta.

Suparta, N. 2005. Pendekatan Holistik Mambangun Agribisnis.Cetakan I, Juni 2005. Denpasar: CV Bali Media Adhikarsa.

Suparta, N. dan I Wayan Ramantha. 2010. Manajemen Bisnis Kecil \& Kewirausahaan. Cetakan Pertama, Juni 2010. Denpasar: Pustaka Nayottama. 